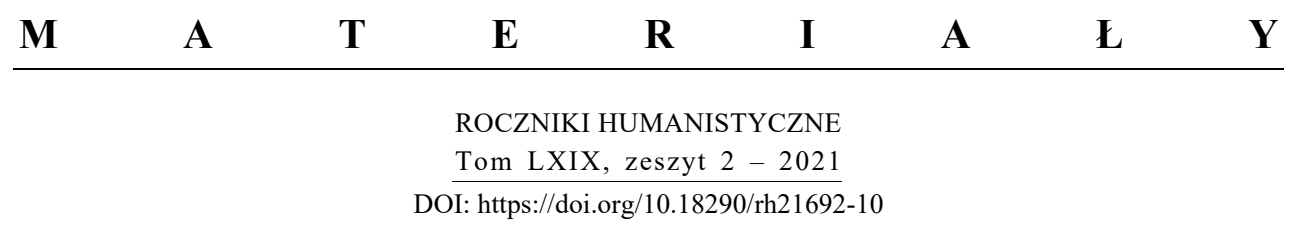

EUGENIUSZ NIEBELSKI

\title{
RAPORT O STANIE POŁOŻENIA POLITYCZNYCH ZESŁAŃCÓW POSTYCZNIOWYCH - KATORŻNIKÓW W KRAJU ZABAJKALSKIM W 1867 ROKU
}

Dokument poniżej prezentowany pochodzi ze zbiorów Państwowego Archiwum Czytyńskiego Obwodu (Gosudarstwiennyj archiw Czitinskoj obłasti GACzO) w Czycie za Bajkałem; notowany w zespole (fond) 1, politycznym, w inwentarzu (opis') 2, w tomie (dieło) 52, na kartach 244-250. Jest to raport z 14 lipca 1867 r. ppłk. Michaiła Kupienkowa (wcześniej piszącego się Kupienko), oficera specjalnych poruczeń, kierującego Tymczasowym Urzędem do spraw nadzoru nad politycznymi zesłańcami w Syberii Wschodniej, adresowany do syberyjskich władz wyższych w Irkucku, imiennie do generała-gubernatora Nikołaja Sinielnikowa, przewodniczącego Komitetu Głównego Urzędu Syberii Wschodniej (Gławnoje uprawlenije Wostocznoj Sibiri). Dokument dotyczy rozmieszczenia zesłańców w Obwodzie Zabajkalskim, miejsc ich osadzenia, liczebności, wykonywanych prac katorżnych, stanu nastrojów itp. Wyjątkowo ważny dla losów polskich zesłańców na Syberii Wschodniej, a w szczególności dla zasądzonych na ciężkie roboty na terenach wschodnich za Bajkałem.

Raport powstał dokładnie rok po wydarzeniach związanych z polskim powstaniem nad Bajkałem w lipcu (według st. st. 24 czerwca) 1866 r., co w tekście ma też swoje odniesienia - chodziło głównie o sprawdzenie stanu nastrojów politycznych wśród katorżników na Zabajkalu oraz wzmożenie dozoru i obserwacji mających zapobiegać wszelkim podobnym buntom w przyszłości.

Prof. dr hab. EugEnIUSz NiebelSKI - Katedra Historii XIX wieku, Wydział Nauk Humanistycznych Katolickiego Uniwersytetu Lubelskiego Jana Pawła II; adres do korespondencji: Al. Racławickie 14, 20-950 Lublin; niebel@kul.pl; ORCID: https://orcid.org/0000-0003-2668-6920. 
Według raportu na opisywanym terenie w dniu 14 lipca 1867 r. miało przebywać w sumie 1184 zesłańców (dwie grupy $649+535$ ), strzeżonych przez 853 żołnierzy i kozaków, co jednakże nie zgadza się z danymi szczegółowymi zamieszczonymi obok. Wkradły się do nich błędy, a definitywne rozstrzygnięcie o przyczynie nieścisłości na obecnym etapie naszych ustaleń nie jest możliwe; prawdopodobnie źle zsumowano dane, albo też pominięto jakieś wykazy szczegółowe (logiczna wydaje się pierwsza przyczyna). Z naszych wyliczeń wynika bowiem, że katorżników na Zabajkalu było $1179(644+535)$, a nie 1184, natomiast konwoju $918(839+79)$, a nie 853. Dla ewentualnych cytowań na potrzeby naukowe bezpiecznie więc byłoby przyjąć, że w lipcu 1867 r. na tamtym terenie znajdowało się około 1180 zesłańców, a strzegło ich blisko 920 żołnierzy konwoju.

Zesłańcy-katorżnicy, w tym z całą pewnością również niektórzy uczestnicy powstania nad Bajkałem ${ }^{1}$, rozmieszczeni byli w opisywanym roku w 12 miejscowościach terenów zabajkalskich, w tym tak wówczas znanych (a dziś także w literaturze opisywanych), jak: Nerczyński Zawod, Akatuj, Siwakowa, Czyta, Pietrowsk, Kadaja, Kara i Darasuń. Miejsca najliczniejszych skupisk to: Siwakowa (stocznia barek rzecznych) - znajdowało się tam 248 zesłańców, Aleksandrowski Zawod - 199, zakład produkcji żelaza w Pietrowsku - 191, kopalnia rudy w Kadai - 112 oraz przy budowie drogi (przypuszczalnie tej, którą zaczynali budować „,buntownicy” 1866 r.) - 148 zesłańców. Warto wymienić jeszcze posłanych do kopalń złota na rzece Kara - 34 zesłańców oraz do miejscowości z wodami zdrojowymi Darasuń - 40 ludzi, pośród których byli tam wtedy m.in. Mikołaj Hartung, Wiktor Godlewski, Aleksander Czekanowski oraz Benedykt Dybowski, mający zgodę władz syberyjskich na usprawnienie i unowocześnienie tamtejszego uzdrowiska² .

Licząc według wielkości zasądzonej kary ciężkich robót, najliczniejszą grupę stanowili zesłańcy skazani na 4 do 6 lat - było ich w sumie 905, skazanych na lat 10 i powyżej było 142 . Pamiętać przy tym trzeba, że były to wyroki już obniżone w ramach amnestii carskiej z kwietnia 1866 r. Raport rejestruje jeszcze osobno księży katolickich w Akatui (miejsce o najostrzejszym rygorze więziennym) - 64 oraz wszelkich obcokrajowców obliczanych na 56 osób, w tym najliczniejszą grupę stanowili poddani austriaccy - 34 .

\footnotetext{
${ }^{1}$ O powstaniu i losach jego uczestników zob. E. NIEBELSKI, „Lepsza nam kula niźli takie życie”. Polskie powstanie nad Bajkatem w 1866 roku, wyd. 2 (Lublin: Polihymnia, 2018).

2 O pracach Dybowskiego i jego współpracowników w Darasuniu dla unowocześnienia tamtejszego uzdrowiska zob. G. BRZĘK, Benedykt Dybowski. Życie i dzieło (Warszawa-Wrocław: Polskie Towarzystwo Ludoznawcze, 1994), 190 i n.
} 
W latach 1867-1868 wszyscy duchowni zostali odesłani z Akatui do wsi Tunka, leżącej około 180 km na zachód od Irkucka, w której izolowano księży wcześniej rozrzuconych po całej Syberii Wschodniej, natomiast wszyscy obcokrajowcy zostali prawdopodobnie zwolnieni i z zesłania, i z Rosji ${ }^{3}$.

Warto jeszcze zaznaczyć, że opisywane Zabajkale to najważniejsze miejsce na Syberii Wschodniej z głównymi katorgami, gdzie odsyłano na najcięższe kary przymusowych robót. Według danych moskiewskich, przytoczonych przez Henryka Skoka, w Zabajkalskiej Obłasti w 1865 r. zgromadzono 1560 katorżników ${ }^{4}$. Skądinąd wiadomo, że władze miały duże problemy z ich rozmieszczeniem i wyegzekwowaniem nakazanych kar, brakowało bowiem nie tylko pomieszczeń więziennych, ale dla wielu skazańców także pracy ${ }^{5}$. Na mocy carskiej amnestii z kwietnia $1866 \mathrm{r}$. zwolniono całkowicie z katorgi na Syberii Wschodniej 813 osób (z sumy 3133 objętych amnestią) ${ }^{6}$, ale jeszcze w 1867 władze syberyjskie borykały się z podobnymi problemami. Autor cytowanego tu raportu wyraźnie o tym wspomina, zwraca też uwagę na potrzebę większego dozoru nad niektórymi skazańcami, uspokajając jednocześnie, że buntu w katorgach raczej nie należy się obawiać.

Dla zobrazowania wielkości zesłań na Syberię Wschodnią w ogóle podajemy jeszcze nieco danych liczbowych wydobytych z archiwów Irkucka i Czyty. Do 27 czerwca 1865 r. w tej części Syberii znalazło się 4246 zesłańców, w tym 2149 katorżników i 1550 osiedleńców pozbawionych praw (pośród nich znajdowało się 1144 cudzoziemców: 1119 poddanych austriackich, 17 pruskich, 6 francuskich, 1 włoski i 1 saksoński). Do 1 stycznia 1866 r. na Syberię Wschodnią przeznaczono 10100 przestępców politycznych wszystkich kategorii. Dnia 3 sierpnia 1867 r. było tam 7068 politycznych (w gub. Jenisejskiej 3352 osoby, w Irkuckiej - 2505, w Zabajkalskiej Obłasti - 1184, w Jakuckiej - 27); w końcu tegoż roku wszystkich zesłańców szacowano na 7129 osób (katorżników, osiedleńców oraz skazanych na zamieszkanie zarówno

\footnotetext{
${ }^{3} \mathrm{O}$ wymienionych problemach zob. stosowną literaturę: E. NIEBELSKI, Tunka. Syberyjskie losy księży zesłańców 1863 roku (Wrocław: Polskie Towarzystwo Ludoznawcze, 2011); M. MicińsKA, Galicjanie - zestańcy po powstaniu styczniowym. Zestanie w głąb Cesarstwa Rosyjskiego Działalność księdza Ludwika Ruczki - Powroty (Warszawa: Wydawnictwo DiG, 2004).

${ }^{4}$ H. SKoK, Polacy nad Bajkatem 1863-1883 (Warszawa: Państwowe Wydawnictwo Naukowe, 1974), 115-116

5 Por. Gosudarstwiennyh archiw Irkutskoj obłast (GAIO), f. 24, o. 3, d. 5 (karton 1758), k. 1, 456; GACzO, f. 1 (p.), o. 2, d. 57 OC, k. 13; tamże, f. 1 (obszczij), d. 141, k. 52-94; zob. też NiEBELSKI, Tunka, 40, przypis $58 \mathrm{i} \mathrm{n}$.

${ }^{6}$ Dane przytoczone przez generała-gubernatora M. Korsakowa 27 maja 1866 r. w raporcie do MSW, GAIO, f. 24, o. 3, d. 62 (karton 1765), k. 16.
} 
wyrokiem sądu, jak też decyzją administracyjną), w tym katorżników pozbawionych praw - 2582 osoby $^{7}$. Na dzień kolejnej amnestii carskiej z 25 maja 1868 r. w Syberii Wschodniej doliczono się 2396 katorżników (w gub. Jenisejskiej i Irkuckiej, w Obłasti Zabajkalskiej i Jakuckiej - w tej tylko 2 osoby), $\mathrm{z}$ tego uwolniono od robót 1065 osób, pozostało jeszcze $1331^{8}$.

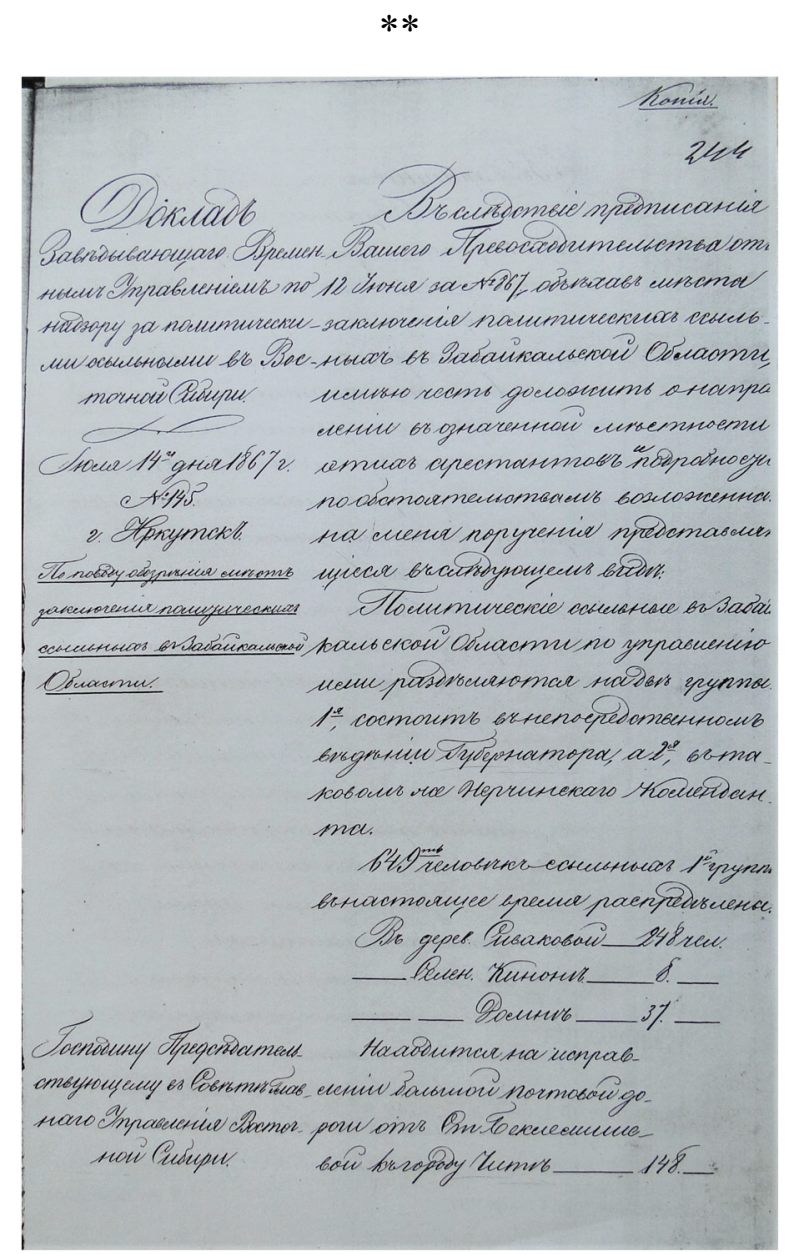

Fot. 1. Pierwsza strona cytowanego raportu (GAIO)

${ }^{7}$ GAIO, f. 24, o. 3, d. 16 (karton 2227), k. 9-10v; tamże, d. 33b, cz. 1 (karton 1763), k. 11-12; tamże, d. 162 (karton 1774), k. 39-43; tamże, d. 37 (karton 1763), k. 235; GACzO, f. 1 (p.), o. 2, d. 52, k. $240-242 \mathrm{v}$.

${ }^{8}$ GAIO, f. 24, o. 3, d. 173 (karton 1774), k. 149-150. 
Доклад

Заведывающаго Временным

Управлением по надзору за политическими ссыльными в Восточной Сибирии

Июля 14플 дня 1867 г.

№ 145

Г. Иркутск

По поводу обозрения мест заключения

политических ссыльных

в Забайкальской Области
Вследствие предписания Вашего Превосходительства от 12 Июля за № 867, обьехав места заключения политических ссыльных в Забайкальской Области, имею честь доложить о направлении в означенной местности этих арестантов и подробности по обстоятельствам возложенного на меня поручения представляющиеся в следующем виде:

Господину Председательствующему в Совете

Главнаго Управления Восточной Сибирии

Политические ссыльные в Забайкальской Области по управлению ими разделяются на две группы: 1ㅛㅡ, состоит в непосредственном ведении Губернатора, а 2-я, в таковом же Нерчинскаго Коменданта.

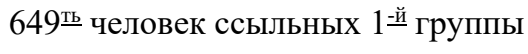

в настоящее время распределены:

$$
\begin{array}{cr}
\text { В дерев. Сиваковой } & -248 \text { чел. } \\
- \text { селен. Киноне } & -8- \\
- \text { Ромне } & -37-
\end{array}
$$

Находится на исправлении большой почтовой дороги от Ст. Беклемишевой к городу Чите $-148-$

$$
\begin{array}{lr}
\text { В Дарасуне } & -40 \text { чел. } \\
\text { гавани в Стретенское } & -12-
\end{array}
$$

На Карийских золотых пр. местах - $34-$

В Петровском железоделательном заводе - 117 -

Люди эти помещены частью в зданиях приспособленных к тюрьмам, части же в землянках окруженных общим забором и шелашах. Некоторые из ссыльных этой группы, окончившие срок исполтания и освобожденные в следствие того из тюремнаго заключения, выстроили на свой счет дома в которых и проживают. Особенное внимание между ними по благоустройству своему заслуживают ссыльные находящиеся в с. Дарасуне, Сиваковой и Киноне, имеющие независимо домохозяйства, хлебопашество и значительные огороды на землях указанных им Начальством в близи своего помещения.

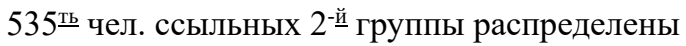
по Нерчинскому Горному Округу в следующих пунктах:

В Александровском заводе 225 чел.

$$
\text { - Акатуевском руднике - } 83 \text { - }
$$


- Алгачинском $\quad-75$ -

В Кадаинском руднике 112 чел.

- с. Красноярове - 40 -

Эти ссыльные содержатся в тюрмах. Для содержания всех поименованных арестантов в местах их содержания имеется конвой в следующем размере:

$$
\begin{array}{r}
\text { В Сиваковой }-190 \text { чел. } \\
- \text { Домне }-29- \\
- \text { Петровском заводе }-74- \\
\text { На дороге }-115- \\
\text { В с. Дарасуне }-14- \\
- \text { Александровском заводе }-147- \\
- \text { Акатуевском руднике }-89- \\
- \text { Кадаинском }-93- \\
- \text { Алгачинском }-76- \\
- \text { Красноярове }-12-
\end{array}
$$

Кроме выше обозначеннаго числа конвоя в Нерчинском Округе состоят на рудниках запасныя команды козаков, простирающиеся до 79 человек. На Карийских промыслах и в Стретенске особаго конвоя для политических ссыльных не имеется, так как на $1^{\mathrm{x}}$ они конвоируются вместе с арестантскими гражданскаго ведомства, а на гавани казаками на службе при ней состоящими.

Сравнивая общую цыфру политических арестантов находящих в Области 1184 челов. с числом конвоя 853 при них состоящаго, можно утвердительно сказать, что вооруженной силы для подавления безпорядков, если бы таковые со стороны арестантов были задуманы, вполне достаточно, но по мнению моему, предполагать какие бы то ни было безпорядки в массе ссыльных по существующему настроению нет основания.

Из собранных мною сведений оказывается, что арестанты везде ведут себя тихо, покорно исполняют требования Начальства и если проявляются между ними случаи неповиновения или нарушения дисциплины и устава о содержащихся под стражей, то случаи эти имеют совершенно частный характер и не могут быть отнесены к задуманному плану неприязненных против Правительства действий. Лучшею мерою для уничтожения злоумышлений оказывается внезапное арестование и перевод в другия места лиц играющих между ссыльными товарищами роль по своему развитию и влиянию; подобныя действия со стороны Начальства возбуждая опасения между ссыльными, ставят каждаго из них, так сказать, в охранительное 
положение и заставляют на долгое время модей с буйным направлением быть сдержанные и не рисковать ради поддержания товарищества собственно особой. Таким образом уничтожая коновводовв можно разстраивать и общность задуманнаго дела.

По срокам пребывания в работах политические арестанты, за воспоследованием 16. Апреля минувшаго года Высочайшей милости, даровавшей сокращение назначеннаго приговора и времени работ на половину, могут быть подразделяемы на следующия категории:

$$
\begin{aligned}
& \text { Сосланных на } 3 / 2 \text { года } 18 \text { чел. } \\
& \text { - } 4 \text { и 4/2 - 350- } \\
& \text { - } 5-268- \\
& \text { - } 6 \text { - } 287 \text { - } \\
& \text { Сосланных на } 7 \text { лет }-3 \text { чел. } \\
& \text { - } 7 / 2-83- \\
& -8-19- \\
& -9-1- \\
& -10-82- \\
& \text { На срок более } 10^{\text {ти }}-60- \\
& \text { Неизвестн. сроков - } 18-
\end{aligned}
$$

В числе состоящих в Забайкальской Области политических ссыльных находится иностранных подданных:

$$
\begin{array}{r}
\text { Французских }-1 \text { чел. } \\
\text { Австрийских }-34- \\
\text { Прусских }-17- \\
\text { Швейцарских }-3- \\
\text { Гессен-Дармштадтских }-1 \text { - }
\end{array}
$$

Лиц происходящих из духовнаго звания

Государственных преступн.
-64 чел. $-18$

Последние сосредоточены в Александровском Заводе, а ссыльные духовнаго звания отделены от других и содержаются в Акатуевском руднике.

При скоплении в Забайкальской Области до 1200 челов. политических ссыльных занимать их ежедневно работам, как того требует закон, по неимению таковых в Области, не представляется возможным; на этом основании местныя Начальства вынуждены употреблять их, за некоторым исключением, в работы по частям заставляя на Нерчинских рудниках 
разбирать руды, исполнять работы по устройтсву тюрем, обведению их канавами и исправлением дорог к тюрьмам пролегающих.

В отношение работ ссыльные состоящие в непосредственном ведении Губернатора обставлены более удовлетворительно, так ссыльные находящиеся на Карийских промыслах, Стретенской гавани, Петровском заводе и на исправление трактовой дороги работают ежедневно и нельзя сказать, чтобы работа их была не производительна.

Работающие на трактовой дороги во время моего проезда были раз-

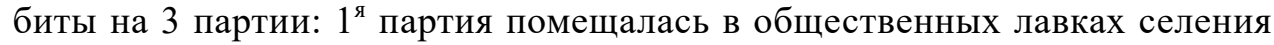
Беклемишевскаго и вела дорогу по селению и за него по направлению к Верхнеудинску, вторая партия от ст. Ключевской к ст. Беклемишевой и 3. партия за ст. Ключевской по направлению к г. Чите, последния партия помещаются в переносных шалашах передвигая их постоянно к месту ведения работ.

В отношение порядка соблюдаемаго при работах почти не остается желать ничего лучшаго, постоянное присутствие на работах офицеров, строгое соблюдение конвоем своих обязанностей и распорядительность Эсаула Соколова, начальствующаго этими ссыльными, не позваляет последним иметь сообщение с посторонными лицами, а неуклонная справедливость означеннаго офицера не дает ссыльным права расчитывать на какое бы то ни было послабление или притеснение. Нельзя умолчать также о ссыльных отряда исправляющихся, находящихся на Дарасунских минеральных водах, в непродолжительном времени устроивших весьма хорошо свое положение чрез заведение домохозяйства и отличающихся по засвидительствованию Начальника Области безукоризненным поведением.

В отношении гигеническом политические ссыльные во всех местах Области находятся в весьма удовлетворительном состоянии в подтверждении чего можно привести небольшой процент больных к общему числу арестантов.

На 1184 человека состояло больных до 25 человек. Требующие медицинской помощи арестанты пользуются ею или в околодках устроенных почти во всяком тюремном помещении или в лазаретах, местах нахождения ссыльных состоящих и законно обставленных как в медицинском, так и в хозяйственном отношении. Пищу и одежду политические ссыльные получают согласно существующих распоряжений; но в отношении выдачи последней при приведении в исполнение распоряжения Главнаго Управления от 20 Марта за № 431, относительно снабжения ею не всех арестантов, а только тех, которые по неимению своей, действительно 
нуждаются в казенной встречается немало затруднений нередко порождающих недаразумения между тюремными начальствами и арестантами, предьявляющими, что выходить на работу в своей одежде они не обязаны. В отстранение сего я полагал бы полезным распоряжение это отменить, так как экономия происходящая от того для казны не может окупать того невыгоднаго нравственнаго значения подрывающаго доверие арестантов к справедливости начальства, которое, по мнению моему, должна быть основанием в управлении ими.

Для отделения из общаго содержания политических ссыльных лиц имеющих дурное влияние на товарищей почти при каждом тюремном помещении устроена одиночныя заключения; но к сожалению не одно из них не удовлетворяет вполне своему назначению; некоторые из них слишком тесны, неснабжены достаточно светом, а главное представляют арестантам возможность слушать разговоры происходящие в кордегардиях, в близи которых за малым исключением они устроены, и даже входить самым в разговоры со стражей.

Убежденный лично в карательном влиянии на арестантов одиночнаго заключения, я позволю себе думать, что увеличение числа одиночных камер устроенных согласно требованию современной науки, в самом непродолжительном времени оказало бы пользу в исправлении строптивых по характеру политических ссыльных тем более, что мера наказания этого, имея много степеней, легче может быть применима в соответствующем размере повиновности каждаго и менее других оставляет в арестанте неприязнь к начальнику назначившему наказание.

В этих видах мне кажется было бы полезно устроить в виде опыта человек на 25 хотя одну тюрьму с одиночными заключениями в Александровском заводе, Нерчинскаго Округа, как в центре сосредоточения более важных преступников и постоянном месте пребывания Коменданта, под непосредственным надзором котораго всегда будут таким образом сгрупированы более важные арестанты.

Обращаясь затем к мерам поощрения, я полагаю, что предоставление политическим ссыльным права в выходом в отряд исправляющихся проживать вне тюрем, сможет принести большую долю пользы сделав положение арестанта менее безнадежным и способным видеть в недалеком будущем облегчение своей участи; приняв же во внимание, что замеченный или подозренный в чем либо арестант во всякое время может быть обращен в тюрьму; нельзя предположить, что злоупотребление этим облегчением может быть продолжительно. 
В заключение имею честь доложить, что 40 человек неспособных к работам политических ссыльных находящихся на содержании в сел. Краснояровом во избежание излишних для казны расходов без особаго затруднения могут быть размещены по другим тюрьмам в ведении Нерчинскаго Коменданта находящимся.

О затруднениях встречаемых Комендантским Управлением в принятии от Нерчинскаго Горнаго Правления всей хозяйственной части по содержанию политических ссыльных и зданий для помещения их и конвоя, я буду иметь честь войдти к Вашему Превосходительству с особым докладом. Подписал:

\section{Подполковник Купенков}

Верно: Исправляющий должность Делопроизводителя А. Фити..... 9

\footnotetext{
${ }^{9}$ Podpis nieczytelny.
} 